\title{
INTEGRATED ECONOMIC AND ENVIRONMENTAL ASSESSMENT OF NITROGENOUS FERTILIZER APPLICATION IN CANADIAN PRAIRIES
}

Suren Kulshreshtha ${ }^{1}$

\begin{abstract}
Adoption of mitigation measures to reduce greenhouse gas emissions may affect other members of the society, producing a situation of trade-offs. In this study, such a trade-off is has been analyzed using three aspects of the Canadian society: producers (farm level adopter), environment (through reduction in the GHG emissions),; and regional economy (including rest of the society through lost / gained economic activities). The nutrient management strategy involving the switching nitrogen fertilizer application from a combination of fall and spring application to a 100 percent spring application. Results suggest that the adoption of such a measure creates a 'win-win' situation, being both environmentally and economically desirable. Under the scenario, fertilizer expenditures decreased by $\$ 43$ million (giving rise to an equivalent increase in farm income), GHG emissions (in CO2E) by 2.15 percent of the 2000 level of emissions, Canadian economy as a whole showed improvements, although on a regional basis the results were mixed.
\end{abstract}

Key words: Canadian prairie agriculture, greenhouse gases, mitigation, nitrogen fertilizer use, trade-off analysis.

\section{INTRODUCTION}

In 1997 Canada signed the Kyoto Protocol and committed to a six percent reduction in greenhouse gas (GHG) emissions from the 1990 level. With the proceedings of the 2009 Copenhagen Accord, this commitment is no longer a binding, but it will mostly likely be replaced by a new commitment ${ }^{2}$. In the mean time, Canadian GHG emission levels have been increasing. For example, in 1990 Canadian GHG emissions were estimated to be at 596.0 megatonne $(\mathrm{Mt})$ Carbon Dioxide Equivalent $\left(\mathrm{CO}_{2 \mathrm{E}}\right)$, which by 2007 rose to $747 \mathrm{Mt}$ - an increase of 25.3 percent\% over the 1990 level (Environment Canada, 2009). Although emissions are increasing now at slower rates than during 1990-2000 period, as shown in AppendixAnnex 1 , by 2020 Canadian GHG could reach $824 \mathrm{Mt} \mathrm{CO}_{2 \mathrm{E}}$. Under the present commitment, this would mean that emissions would have to be reduced by $217 \mathrm{Mt} \mathrm{CO}_{2 \mathrm{E}}$ or 29 percent\% of the 2005 level.

Canada's commitment to reduce GHG at some future date requires some knowledge of its likely impact on the society either directly or through environmental aspects. Many previous studies have examined the potential impact of agriculture mitigation measures in reducing GHG emissions. For example, study of GHG mitigation measures have been reported by Sims (2003), and Tuhkanen, Lehtila, and Savolainen et al. (1999). Sims (2003) investigated the role played by bioenergy in mitigating GHG emissions, and identified economic, environmental and social benefits from bioenergy development, trade-offs from such adoption were neither identified nor measured. Similarly, other studies have focused on environmental impacts, while overlooking economic impacts resulting from their implementation. Examples of such studies include Babcock et al. (2001), Baker and Murray, (2009), Riedacker, (2007), Flessa et al., (2002), Pant, (2009)). Carbon sequestration has also been studied by Stinson and Freedman (2001), and Marland, Schlamadinger and Canella

\footnotetext{
${ }^{1}$ Department of Bioresource Policy, Business and Economics, University of Saskatchewan, Saskatoon, Canada, Email: suren.kulshreshtha@usask.ca.

${ }^{2}$ Recent announcement by the Government of Canada indicates that the new deal may be to reduce GHG emissions from the Canadian economy by $17 \%$ of the 2005 level by 2020 .
} 
et al. (1997). Such sequestration measures are complementary to mitigation measures since they all lead to either permanent or temporary reduction in the level of GHG emissions. For example, use of zero tillage is a common mitigation measure endorsed for such sequestration activities, which could conceivably crate create trade-off situation. Other studies have also investigated waste management (Pipatti and Wihersaari, 19971998), but with no assessment of trade-offs.

In Canada, Khakbazan et al. (2004) have evaluated the performance o of two farming systems in terms of their GHG emissions, with no economic or social impacts considered. Meyer-Aurich (2004) reported best management practices that reduce GHG emission in eastern Canada. A similar study by Smith and Upadhyay (2005) reported such practices on diversified farms in western Canada. These studies have addressed only the biophysical aspects of mitigation and sequestration.

Linking agriculture with environment and some social issues, such as poverty reduction, has been reported by Dhakal (2007) and recommended that projects need to examine economic impacts before their final selection. However, there appears to be a need for examining various measures from both bio-physical (leading to environmental) and economic perspectives to examine the possible trade-offs.

Many decision makers are reluctant to recommend a wide adoption of mitigation measures on grounds that it might slow down the economic activities in their own jurisdiction'. This suggests that perhaps for some mitigation measures a trade-off situation may exist. These trade-offs may be in the form of better environmental performance, but at the cost of poor regional economic growth. Examination of such trade-offs for measures designed to reduce agricultural GHG emissions is thus important for policy makers. Such an examination involves development of an analytical framework capable of identifying these trade-offs with the purpose that proper policies and programs can be developed with their likely consequences known a priori before their adoption is endorsed.

Industrial agriculture world over is heavily dependent on the use of inorganic fertilizer to supply crop nutrients. This, on one side, improves the farm cash position but on the other, manufacturing and distribution of fertilizer creates jobs in the regional economy. However, application of fertilizer has impacts on the environment through increased GHG emissions, as well as affects air and water quality.

The purpose of this study was twofoldthreefold to: 1) To estimate the GHG emissions resulting from change in nitrogen fertilizer use on the Canadian prairies; 2 ) To estimate the economic impacts resulting from the changed nitrogen fertilizer use mitigation scenario; and 3) Eexamine the situation of trade-offs that may be created through adoption of these mitigation practice.

\section{SALIENT FEATURES OF NITROGEN FERTILIZER USE IN CANADIAN AGRICULTURE}

Canada's consumption of nitrogen based fertilizers on a global scale was ninth in 2002 at 1.63 Mt (1.9 percent) (FAOSTAT Data 2005), with the majority of the consumption being dominated by agricultural activities. When estimated on per capita basis Canada's nitrogen fertilizer consumption was third at $52.12 \mathrm{~kg}$ per capita ${ }^{2}$. Only Ireland and New Zealand had higher per capita nitrogen fertilizer consumption. The trend in fertilizer use in Canada has increased significantly since 1990 as shown in Fig.1. Although fertilizer sales have slowed

1 One of the arguments frequently given in Canada is that the country cannot afford an aggressive mitigation campaign during the current period on account of current recession.

2 Most of the fertilizer sales are for agricultural production. However, it is acknowledged that a small part of this total may also be used by home gardens and other non-agricultural purposes. 
down a little during the last decade ${ }^{1}$, if the historical trend in nitrogen based fertilizer consumption in Canada were to continue to 2020 period the estimated level of nitrogen fertilizer consumption would be higher than current levels. This significant increase in nitrogen fertilizer consumption for the year 2020 would result in a substantial increase in GHG emissions from nitrogenous fertilizers. Consequently, mitigation scenarios involving nitrogen fertilizer consumption in Canada have become increasingly important.

The regional distribution of Canadian nitrogen fertilizer consumption in 2000 was dominated

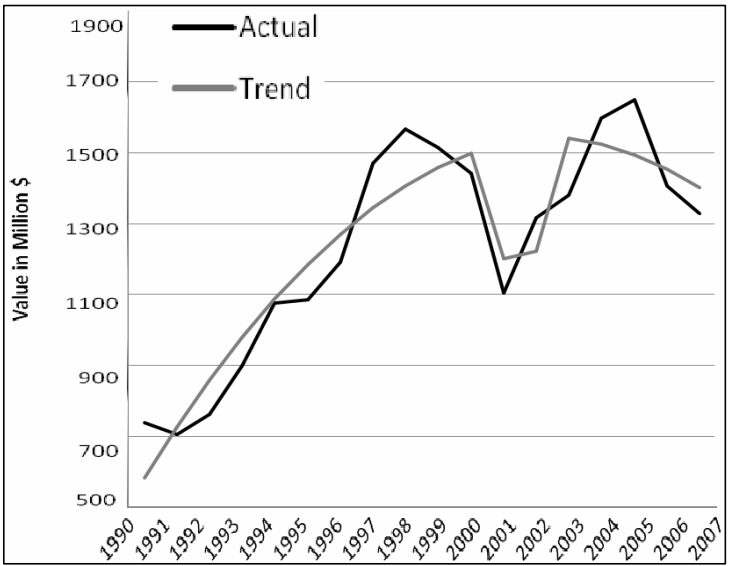
by the prairie provinces of Alberta, Saskatchewan and Manitoba (Fig.2). These three provinces combined for 82 percent of the total nitrogen fertilizer consumed in Canada in $2000^{2}$. Saskatchewan was responsible for 33 percent of the consumption, while Alberta and Manitoba consumed 30 percent and 19 percent, respectively. The dominance of the three Canadian Prairie provinces in nitrogen fertilizer consumption would ultimately lead to a prairie focused nitrogen fertilizer mitigation scenario.

Fig. 1: Total Canadian nitrogen fertilizer consumption from 1990 - 2007 Source: Estimated from Statistics Canada (2010a and b)

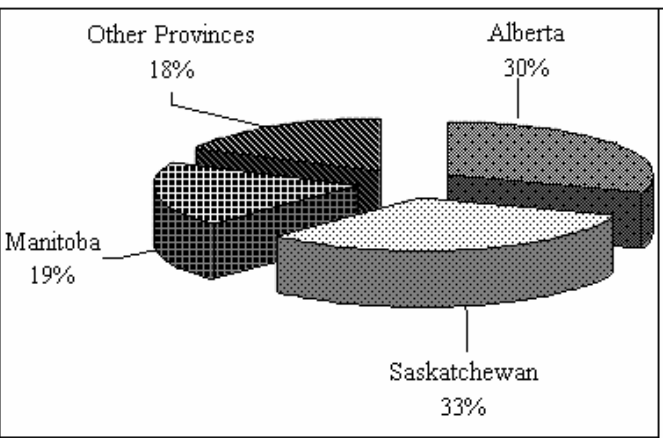

\section{METHODOLOGY}

Most decision makers operate within a multi-decision framework. Here, the decision maker has several criteria that need to be achieved by a given mitigation measure ${ }^{3}$. A situation of a trade-off exists when the decision maker must sacrifice (or accept lower performance for) at least one criterion in order to achieve a gain in another criterion. In contrast, a 'win-win' situation is where all the criteria of the policy maker are met at some acceptable or superior level.

Fig. 2: Provincial distribution of $\mathrm{N}$ - fertilizers in Canada in 2000 (Korol and Rattray, 2001

In this study trade-offs were assessed using three criteria: - change in the farm level economics for the adopter of the GHG mitigation measure; reduction in the level of GHG emissions; and change in the level of regional economic activities. Using these three

Two reasons for this could be advanced: One, the droughts of 2001 and 2002 reduced the need for fertilizer since certain areas were not seeded and farmers' paying capacity was reduced; Two, in more recent period, price of fertilizer increased significantly.

2 Data for recent time period has been suppressed by Statistics Canada to preserve confidentiality. Therefore, data for the year $\mathbf{2 0 0 0}$ are used. It is expected that the pattern of use has not changed appreciably since that time.

3 In fact, the same could be said about any policy measure. 
criteria one can distinguish between a trade-off and a win-win mitigation measure as shown in Fig. 3. The base scenario triangle stands at 100 \%percent of the baseline situation. The dotted-line triangle on the left-hand side of the diagram shows gain in all three criteria, and thus is labeled a 'win-win' scenario. On the other hand, in the third scenario there is a desirable change in GHG emissions, but a loss to the producers. This illustrates that there is a trade-off between environment and farm level economics.

In order to assess the trade-off in the study mitigation practice, three separate but compatible models were interlinked: (1) Canadian Regional Agriculture Model (CRAM); (2) Greenhouse Gas Emissions Model (GHGEM) for Canadian Agriculture,; and (3) Canadian Agriculture Regional Disaggregated Input Output Model (CARDIOM). An overview of tradeoff analysis is shown in Fig.4. Each of these is described below.

\section{CANADIAN REGIONAL AGRICULTURE MODEL (CRAM)}

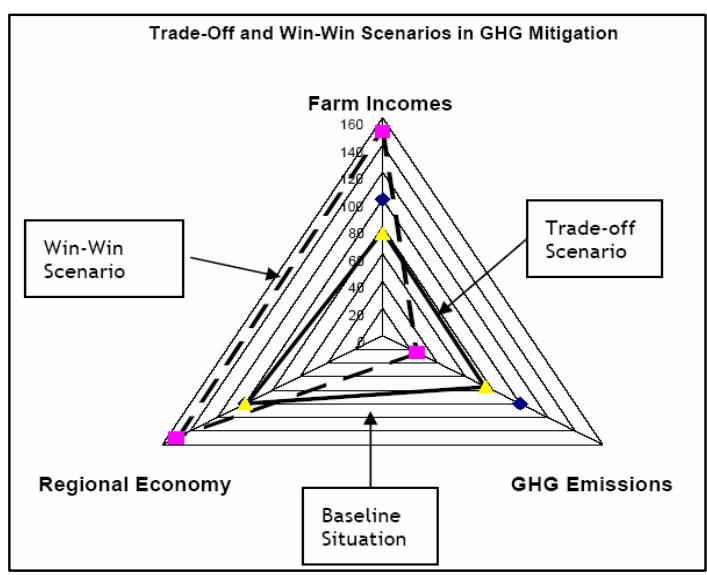

The CRAM is a static non-linear economic optimization model that maximizes a modified welfare function (consumer plus producer surplus less processing and transportation costs) through allocation of agricultural resources and land subject to model constraints facing various sectors of the Canadian agricultural economy (Horner et al., 1992). It allows for both inter-provincial trade and international trade in primary and processed products. The basic commodity coverage is grains and oilseeds, forage, beef, hogs, dairy and poultry.

Fig. 3: Diagrammatic representation of a trade-off and a win-win mitigation scenario with three criteria

The model includes both crop and livestock production, with crop activities being disaggregated into 55 regions and livestock activities disaggregated provincially. The CRAM includes both inter-provincial and international trade in primary and processed agricultural products. The analysis of mitigation scenarios in the CRAM are conducted by comparison of scenario and baseline activity levels. The outputs of the model include level of activities for crops and livestock enterprises, and their respective input use under a given scenario.

\section{GREENHOUSE GAS EMISSIONS MODEL (GHGEM)}

The second sub-model GHGEM is a modular static linear additive calculator of GHG emissions that is linked to the CRAM output. In other words in the absence of the CRAM the GHGEM is unable to produce any results. The GHGEM estimates both backward and forward (food processing and transportation) linkages resulting from agriculture production. More details on the models are presented in Sobool and Kulshreshtha (2005). The accounting structure of the GHGEM is shown in Annex 2.

The GHG emissions are measured at three levels, namely, 1) Intergovernmental Panel on Climate Change (IPCC) level emissions, 2) Total direct farm-level emission, and 3) Agriculture and Aagri-food sSystem (AAFS) level emissions. The GHGEM is designed to estimate the GHG emission that are both directly and indirectly related to agriculture activities. For example the use of fertilizer at the farm level results in IPCC level emissions, namely fertilizer application emissions as well as atmospheric deposition and leaching of 
nitrogen, but to account for the entire AAFS the production and transportation of fertilizer from the manufacturing plant to the wholesaler (distributor) must be included. These indirect emissions are referred to as backward linkages.

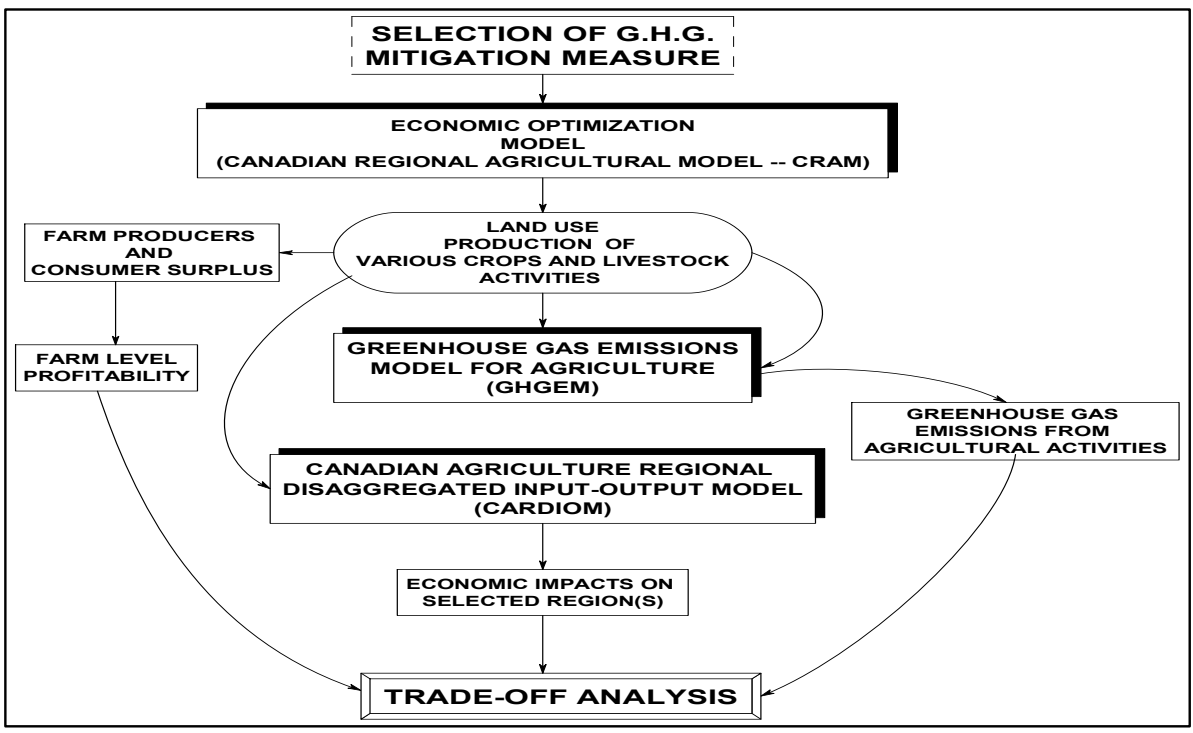

Fig. 4: Overview of trade-off analysis

\section{CANADIAN AGRICULTURE REGIONAL DISAGGREGATED INPUT OUTPUT MODEL (CARDIOM)}

The estimation of the regional economic impacts resulting from the reduced nitrogen fertilizer use scenario involves using the CARDIOM (Sobool and Kulshreshtha, 2006). The CARDIOM is an input-output (I-O) model for the entire Canadian economy disaggregated at the provincial level. The change in economic indicators (such as include value of sales of goods and services, gross domestic product, household incomes, imports from other parts of the world, and employment). Value of sales was estimated from the results of the CRAM, which are converted to the input format of the CARDIOM through an interface module.

The basic structure of the $1-0$ model is based on the transaction tables maintained by Statistics Canada (2001). The main constraint to the Statistics Canada provincial I-O tables was that the agriculture sector was limited to a single industry with only two commodity classifications, while the manufacturing sector was not divided into food and non-food sectors and was limited to four food commodity classifications. To overcome this constraint the CARDIOM disaggregated the agriculture sector into 13 farm types and 11 commodity classifications. The manufacturing sector was divided into 9 nine food and beverage sectors and one non-food manufacturing sector.

The CARDIOM estimates two types of economic impacts resulting from the direct impact data generated through CRAM-Interface module. This model then calculated indirect (called Type I) and induced (Type II) impacts. For example, in a fertilizer scenario, reduction in the fertilizer expenditures, and resulting change in the gross revenues and farm net incomes, are the direct impacts. This reduced demand for nitrogen fertilizer would result in indirect impacts, such as lower output of the fertilizer manufacturing sector. This would trigger lower input demand for this sector, including lower employment of workers. This would result in a chain reaction of lower demand for various goods and services in the economy, including loss of employment of workers. The induced impacts are the economic impacts 
result from change in employment (and thus the household income) first, and then through change in their respective expenditures on goods and services. In the reduction of nitrogen fertilizer scenario, the induced effects would result mainly from change in farm net income and from change income of the workers engaged in various industries affected under the scenario.

\section{SCENARIO DESCRIPTION - NITROGEN FERTILIZER MATCHING}

Most producers apply fertilizer either in the fall or in the spring season. Some of the fertilizer so applied finds its way to the atmosphere through atmospheric deposition or leached to underground receptacles (such as shallow aquifers).

The scenario utilized for estimation of trade-off (or a win-win) situation in reducing GHG emissions from agriculture. The study scenario assumes that current nitrogen fertilizer application on the Canadian prairies is inefficient with respect to its time of application. A typical practice is to have a split application - 30 percent applied in the fall previous to the crop season, and 70 percent as spring application. Spring application of nitrogen fertilizers is considered to be more efficient in terms of nutrients available for crop growth. Thus, shifting away from the fall application improves the technical efficiency of fertilizer used, and therefore, a smaller quantity is required to maintain the same level of yield. However, the downside of this change is that the cost of fertilizer is relatively higher during spring application period than in fall. On average, a 12 percent price premium was noted for spring application (Heigh and Junkins, 2004).

\section{ASSESSMENT OF SCENARIO IMPACTS}

The scenario was analyzed first using the CRAM. Change in the amount of fertilizer and the price paid by producers under the study scenario were estimated. More details on this analysis are presented in Heigh and Junkins (2004). The results from the CRAM were then used in the Interface Module to convert these results into the input-output I-O model final demand. The change in nitrogen fertilizer input demand values were then inputted into the GHGEM and CARDIOM to estimate the resulting GHG emissions and economic impacts, respectively, from the reduced demand for nitrogen fertilizer has in the prairie and Canadian economy.

\section{RESULTS}

The results of the nitrogen fertilizer reduction scenario were examined with respect to their environmental and economic efficiencyies. The first section reports farm level economics under the study scenario. This is followed by an assessment of environmental efficiency of the reduced nitrogen fertilizer scenario in terms of change in the GHG emissions. The third section examines the economic efficiency of the nitrogen fertilizer mitigation scenario in terms of regional impact analysis.

\section{FARM LEVEL IMPACTS}

Reduction in the level of fertilizer applied to the crops with no associated change in the yield of various crops resulted in reduced expenditures on fertilizer of $\$ 43$ million annually in 2006 dollars. Other crop production related expenses remain unchanged. Given that gross revenue does not change under this scenario, the net result is a gain in producer surplus (equivalent to net farm income) of an equivalent amount, as shown in tTable 1.

\section{GREENHOUSE GAS EMISSIONS}

The nitrogen fertilizer reduction scenarios effect on GHG emissions on the Canadian prairies are shown in Ttable 2 . These reductions were a result of both IPCC level (and farm level) as well as at the agri-food system level emissions. These emissions were from three main 
sources: direct emissions from the fertilizer use,; ecosystem level emissions from atmospheric deposition and leaching,; and manufacturing and transportation of fertilizer.

Table 1. Nitrogen fertilizer scenario change in physical and monetary demand, based on CRAM output, 2006

\begin{tabular}{lccc}
\hline Province & $\begin{array}{l}\text { Change in fertilizer } \\
\text { consumption }(\mathrm{t})\end{array}$ & $\begin{array}{l}\text { \% Change in fertilizer consumption } \\
\text { from Without Scenario Levels }\end{array}$ & $\begin{array}{l}\text { Change in fertilizer } \\
\text { input demand }(\$ 000)\end{array}$ \\
\hline Alberta & $-36,795$ & $-7.2 \%$ & $-\$ 15,360$ \\
Saskatchewan & $-32,229$ & $-5.9 \%$ & $-\$ 14,320$ \\
Manitoba & $-26,091$ & $-8.0 \%$ & $-\$ 13,470$ \\
Total Prairies & $-95,115$ & $-6.9 \%$ & $-\$ 43,150$ \\
\hline
\end{tabular}

Table 2. Net change in GHG emissions from fertilizer reduction scenario, in kilotonnes of $\mathrm{CO}_{2 \mathrm{E}}, 2006$ level

\begin{tabular}{l|c|c|c|c}
\hline Category & Alberta & Sask. & Manitoba & Total \\
\hline IPCC Emissions & -114.54 & -99.03 & -100.01 & -313.57 \\
Fertilizer & -17.92 & -15.70 & -12.71 & -46.33 \\
Atmospheric Deposition & -67.22 & -58.88 & -47.66 & -173.75 \\
Nitrogen Leaching & -199.68 & -173.61 & -160.38 & -533.66 \\
Total Net IPCC Emissions & $-1.35 \%$ & $-1.44 \%$ & $-2.19 \%$ & $-1.56 \%$ \\
\% Reduction in IPCC Emissions, \% & -217.12 & -102.95 & -57.92 & -377.99 \\
Agri-Food Sector (AFS) Emissions & -5.74 & -9.63 & -1.02 & -16.39 \\
Fertilizer Production -- Domestic Use & -222.86 & -112.58 & -58.94 & -394.37 \\
Transportation from plant to dealers & $-2.02 \%$ & $-2.63 \%$ & $-3.59 \%$ & $-2.48 \%$ \\
Total Net AFS Emissions & & \\
\% Reduction in AFS Emissions, \% & & \\
Agriculture and Agri-Food Sector (AAFS) Emissions \\
Total Net Emissions for the AAFS & -422.53 & -286.19 & -219.31 & -928.03 \\
\% Reduction in Total AAFS Emissions, \% & $-1.80 \%$ & $-2.15 \%$ & $-3.02 \%$ & $-2.15 \%$ \\
\hline
\end{tabular}

For the entire agriculture and agri-food sector in the Canadian prairies, GHG emissions decreased by 928.03 kilo tonnes ${ }^{1}(\mathrm{kt})$ in Carbon Dioxide Equivalent ${ }^{2}\left(\mathrm{CO}_{2 \mathrm{E}}\right)$, which was 2.15 percent lower than that under the base situation ${ }^{3}$. Largest reduction among the three Prairie Provinces was recorded for Alberta at $422.53 \mathrm{kt}$ of $\mathrm{CO}_{2 \mathrm{E}}$ (constituting a reduction of 1.80 percent from the base situation), followed by Saskatchewan at $286.19 \mathrm{kt}$ ( 2.15 percent lower than the base situation) and finally Manitoba at $219.31 \mathrm{kt}$ (3.02 percent below the base situation).

Little over a third of the total GHG emissions are from reduction in the application of fertilizer, as shown in Fig.5. The largest reduction in the total GHG emissions is through reduced production (manufacturing), storage and transportation of the fertilizer.

1 A kilo-tonne is 1,000 tonnes, which is equivalent to one giga gram $\left(10^{12} \mathrm{~g}\right)$.

2 Carbon dioxide equivalent level of greenhouse gases is obtained by multiplying each gas by its global warming potential (GWP) relative to carbon dioxide. In this study, for methane and nitrous oxide GWP of 21 and 310, respectively, was used.

3 The base situation was that for the farms when the study scenario is not implemented. 


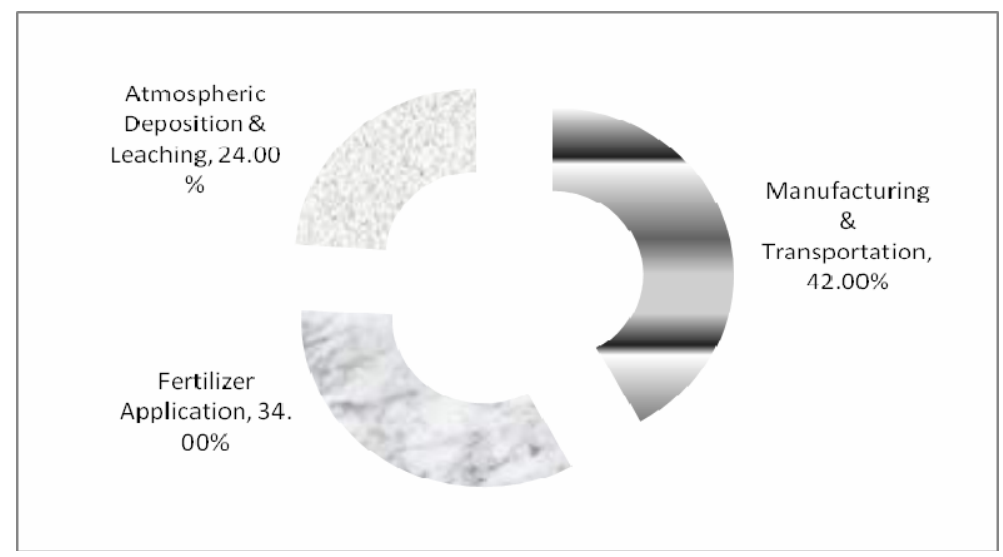

Fig. 5: Distribution of total reduction in GHG emissions under study scenario

\section{REGIONAL ECONOMIC EFFECTS}

The economic impact results from the fertilizer matching scenario are shown in tTable 3 . The results are divided provincially for the prairie region, with aggregate totals for the prairie region and Canada being presented as well. Given the CARDIOM is a multi-regional model the feedback effects are estimated directly. The estimation of the aggregated national feedback effects using the CARDIOM is estimated as the difference between the national economic impact results and the study region results.

As noted above, Type I impacts are a sum of direct and indirect impacts, the latter being created through backward linkages of agricultural production. The Type II impacts include, in addition to Type I impacts, those created by spending of household income on the goods and services. For the prairie region a decrease in fertilizer demand of $\$ 43.15$ million results in loss of direct and indirect impacts on output for the Canadian economy is $\$ 25.74$ million. When factoring in the induced impacts of increased household spending, specifically farm households whose income increased by the same level of the decreased fertilizer demand as shown in Ttable 43, the total economic impact results in increased output of prairie firms by $\$ 18.20$ million. The national level of total economic impact resulted in an increase in the national output of $\$ 9.19$ million. The fact that the prairie region total economic output level is $\$ 9.02$ million higher than the national value indicates that the feedback loss effects are greater outside the prairie region mainly due to the high level of fertilizer imports in the prairie region. The increase in type $\mathrm{I}^{1}$ household income of $\$ 36.79$ million on the prairies results in the GDP at market prices to increase $\$ 30.67$ million, while including the induced impacts results in total prairie income increase of $\$ 51.09$ and GDP at market prices increasing $\$ 55.79$ million. The feedback loss effect for the rest of Canada shows thant total household income decreased $\$ 4.11$ million, resulting in GDP at market prices declining $\$ 5.52$ million.

The effect the fertilizer scenario has on employment results in a loss of 191 jobs directly and indirectly (through backward linkages). Inclusion of the induced impacts results in total employment increasing by 282 jobs for the prairie provinces. For Canada as a whole the

1 Type I economic impacts is estimated when the household incomes are not endogenous. Thus, change in the income of producers has no impact on the regional economy. This is modified in the Type II impacts, which are estimated using household incomes made endogenous in the model. 
direct and indirect jobs losses are 396 workers, while the total number of jobs in Canada increased by 135 . The feedback loss effects for the non-prairie region yields a loss of 205 jobs under the type I impacts, while overall the number of non-prairie jobs fell by 147 .

Table 3: Economic ilmpact aAnalysis rResults for the fFertilizer sScenario, 2006

\begin{tabular}{|c|c|c|c|c|}
\hline Parameter & $\begin{array}{l}\text { Output (\$ } \\
\text { Mill.) }\end{array}$ & $\begin{array}{l}\text { GDP at Market } \\
\text { Price }(\$ \text { Mill.) }\end{array}$ & $\begin{array}{l}\text { Household Income } \\
(\$ \text { Mill.) }\end{array}$ & $\begin{array}{l}\text { Employment } \\
\text { (FTE \# of Workers) }\end{array}$ \\
\hline \multicolumn{5}{|l|}{ Alberta } \\
\hline Direct Economic Impact & $(\$ 15.36)$ & & & \\
\hline Direct \& Indirect Impacts & $(\$ 12.13)$ & $\$ 10.38$ & $\$ 12.73$ & (65) \\
\hline Induced Impacts & $\$ 17.43$ & $\$ 9.69$ & $\$ 5.56$ & 158 \\
\hline Total Impacts & $\$ 5.30$ & $\$ 20.07$ & $\$ 18.29$ & 93 \\
\hline \multicolumn{5}{|l|}{ Saskatchewan } \\
\hline Direct Economic Impact & $(\$ 14.32)$ & & & \\
\hline Direct \& Indirect Impacts & $(\$ 6.44)$ & $\$ 11.02$ & $\$ 12.90$ & (48) \\
\hline Induced Impacts & $\$ 13.76$ & $\$ 7.87$ & $\$ 4.36$ & 162 \\
\hline Total Impacts & $\$ 7.32$ & $\$ 18.86$ & $\$ 17.26$ & 114 \\
\hline \multicolumn{5}{|l|}{ Manitoba } \\
\hline Direct Economic Impact & $(\$ 13.47)$ & & & \\
\hline Direct \& Indirect Impacts & $(\$ 7.18)$ & $\$ 9.27$ & $\$ 11.16$ & (78) \\
\hline Induced Impacts & $\$ 12.76$ & $\$ 7.59$ & $\$ 4.38$ & 153 \\
\hline Total Impacts & $\$ 5.58$ & $\$ 16.86$ & $\$ 15.54$ & 75 \\
\hline \multicolumn{5}{|l|}{ Prairies } \\
\hline Direct Economic Impact & $(\$ 43.15)$ & & & \\
\hline Direct \& Indirect Impacts & $(\$ 25.74)$ & $\$ 30.67$ & $\$ 36.79$ & (191) \\
\hline Induced Impacts & $\$ 43.95$ & $\$ 25.12$ & $\$ 14.30$ & 472 \\
\hline Total Impacts & $\$ 18.20$ & $\$ 55.79$ & $\$ 51.09$ & 282 \\
\hline \multicolumn{5}{|l|}{ Non-Prairie Region } \\
\hline Direct \& Indirect Impacts & $(\$ 21.62)$ & $(\$ 10.89)$ & $(\$ 7.60)$ & (205) \\
\hline Induced Impacts & $\$ 12.60$ & $\$ 5.37$ & $\$ 3.49$ & 58 \\
\hline Total Impacts & $(\$ 9.02)$ & $(\$ 5.52)$ & $(\$ 4.11)$ & (147) \\
\hline \multicolumn{5}{|l|}{ Canada } \\
\hline Direct Economic Impact & $(\$ 43.15)$ & & & \\
\hline Direct \& Indirect Impacts & $(\$ 47.37)$ & $\$ 19.78$ & $\$ 29.20$ & (396) \\
\hline Induced Impacts & $\$ 56.55$ & $\$ 30.49$ & $\$ 17.79$ & 531 \\
\hline Total Impacts & $\$ 9.19$ & $\$ 50.27$ & $\$ 46.98$ & 135 \\
\hline
\end{tabular}

The overall results indicate that the prairie economy positively benefits from the reduced nitrogen fertilizer demand, with increased output, GDP at market prices and increased employment. When factoring in the feedback loss effects for the non-prairie region the total economic impacts for the entire Canadian economy are still positive, despite the economic loss experienced in the non-prairie region.

\section{CONCLUSIONS}

This paper estimated the environmental and economic impacts resulting from a reduction in the use of agricultural nitrogen fertilizer on the Canadian prairies resulting from the switching to a 100 percent spring application using three models. The impact on the farm level resource allocation were estimated using CRAM, while $t$ he environmental impacts were estimated using the GHGEM. Finally the economic impacts were estimated using CARDIOM. The estimation of both the environmental and economic impacts from the nitrogen fertilizer mitigation scenario allowed for estimation of any potential trade-offs between regional development and GHG mitigation. This trade-off analysis is important as 
when examining the overall societal effects of a mitigation scenario as a reduction in GHG emissions may result in significant financial costs to society.

The nitrogen fertilizer reduction scenario is both environmentally and economically feasible. The total reduction in nitrogen fertilizer consumption on the Canadian prairies was over $95.1 \mathrm{kt}(6.9$ percent), while the resulting decreased demand resulted in a decrease in fertilizer expenditures of $\$ 43.15$ million. The reduction of CO2E GHG emissions for the Canadian prairies was $928.03 \mathrm{kt}$ from the baseline levels. This was a reduction of 2.15 percent. The IPCC level CO2E emissions declined $533.66 \mathrm{kt}$ (1.56 percent) and the AAFS emissions were reduced $394.37 \mathrm{kt}$ (2.48 percent).

The non-prairie regions of Canada experienced a decline in economic development from the reduced fertilizer demand but the increase in the prairie region was significant enough to offset the non-prairie region loss. The economic impacts resulting from of the reduced fertilizer demand resulted in increased GDP at market prices of $\$ 50.27$ million. Household income in Canada increased by $\$ 46.98$ million and there were 135 new jobs were created. The direct and indirect impacts to the prairie and Canadian economy suffered a loss from the reduced fertilizer demand but the increase in the induced impacts, which were driven by increase in farm level income, generated enough economic spin-offs to result in an overall net gain to the society.

The results from both the economic and environmental analysis show that both are efficient in increasing societal welfare. While the results are significant on an absolute scale, in relative terms these are borderline insignificant. This does not mean, however, that the reduction of in nitrogen fertilizer use on the Canadian prairies should be ignored but rather the feasibility of expanding the scope and size of the scenario to both further decrease nitrogen fertilizer use and include other provinces should be examined. Nonetheless, examination of changes in both economic and environmental parameters is of interest to the decision makers, and for this reason an assessment should be based on the proposed integrated manner.

\section{REFERENCE}

Babcock, B. A., J. C. Beghin, M. Duffy, H. Feng, B. Hueth, C. Kling, L. Kurkalova, U. Schneider, S. Secchi, Q. Wenninger, and J. Zhao,. 2001. Conservation payments: challenges in design and implementation. CARD Briefing paper. Ames: Center for Agricultural and Rural Development, lowa State University. 27 pp.

Baker, J. and B. Murray. 2009. Groundwater management in the presence of greenhouse gas mitigation incentives for agriculture. Paper presented at the 2009 Annual Meeting of the Agricultural and Applied Economics Association. Milwaukee, Wisconsin. 46 pp.

Dhakal, N., 2007. Agriculture and environment: interlink with poverty dimension. The Jour. of Agric. and Environment, 8:74-82.

Environment Canada. 2009. National Inventory Report, 1990-2006: Greenhouse Gas Sources and Sinks in Canada. Ottawa.

Flessa, H., R. Ruser, P. Dorsch, T. Kamp, M. Jimenez, J. Munch and F. Beese. 2002. Integrated evaluation of greenhouse gas emissions $\left(\mathrm{CO}_{2}, \mathrm{CH}_{4}, \mathrm{~N}_{2} \mathrm{O}\right)$ from two farming systems in southern Germany. Agric. Ecosystem and Environment, 91:175-189.

FAOSTAT Data: 2005. “Agricultural data: fertilizers." Available at: http: / / faostat.fao.org/faostat/collections?subset=agriculture.

Heigh, L. and B. Junkins, : 2005. Quantitative analysis of the impact of agricultural management strategies on environmental indicators. Research and Analysis Directorate, Strategic Policy Branch, Agriculture and Agri-Food Canada. Ottawa, ON.

Horner, G.L., J. Corman, R. E. Howitt, C. A. Carter and R.J MacGregor, R.J.: . 1992. “The Canadian regional agriculture model: Structure, operation and development." Policy Branch, Agriculture Canada, Technical Report 1/92. Ottawa, ON. 
Khakbazan, M., M. Monreal, D. Derksen and R. Zentner. 2004. Evaluating economics of greenhouse gas emissions under high and low inputs farming systems. Paper presented at the NAREA-CAES Conference, June 2004, Halifax, Nova Scotia, Canada. 16 pp.

Marland, G., B. Schlamadinger and L. Canella, L.: . 1997. Forest management for Mitigation of $\mathrm{CO}_{2}$ emissions: How much mitigation and who gets the credits? Mitigation and Adaptation Strategies for Climate Change, 2:303-318.

Meyer-Aurich, A., A. Weersink, S. Jayasundara, and C. Wagner-Riddle. 2004. Effectiveness of best management cropping systems to abate greenhouse gas emissions. Current Agriculture, Food and Resource Issues. 5:1-9.

Pant, K. P., 2009. Effects of agriculture on climate change: a cross country study of factors affecting carbon emissions. The Jour. of Agric. and Environment, 10:72-88.

Pipatti, R. and M. Wihersaari, M.: . 1997-1998. Cost-effectiveness of alternative strategies in mitigating the greenhouse impact of waste management in three communities of different size. Mitigation and Adaptation Strategies for Global Change, 2: 337-358.

Riedacker, A., 2007. A global land use and biomass approach to reduce greenhouse gas emissions, fossil fuels use ad to preserve biodiversity. Climate change modeling and policy working papers. Available at: http://purl.umn.edu/9551.

Sims, R.E. H. 2003. Bioenergy to mitigate for climate change and meet the needs of society, the economy and the environment. Mitigation and Adaptation Strategies for Global Change, 8:349-370.

Smith, E. G. and B. M. Upadhyay, 2005. Greenhouse gas mitigation on diversified farms. Paper presented at the Annual Meeting of the Canadian Agricultural Economics Society, July 2005. San Francisco, CA. 16 pp.

Sobool, D. and S. Kulshreshtha, S., 2005. Greenhouse gas emissions from Canadian agriculture model (2000): Technical documentation. Department of Agricultural Economics, University of Saskatchewan. Saskatoon, SK.

Sobool, D. and S. Kulshreshtha, S., 2006. "Canadian disaggregated regional input output model." Department of Agricultural Economics, University of Saskatchewan. Saskatoon, SK.

Statistics Canada, 2001. "Inputs and outputs, by sector and commodity, S-level aggregation and North American Sector Classification System (NAICS) - 2000." Table 381-0013. Available at: http://estat.statcan.ca/. Ottawa, ON.

Statistics Canada. 2010a. Annual survey of manufacturers. CANSIM Table No. 301-0003. Available at: http://estat.statcan.ca/. Ottawa, ON.

Statistics Canada. 2010b. Principal statistics for manufacturing industries. CANSIM Table No. 301-0006. Available at: http://estat.statcan.ca/. Ottawa, ON.

Stinson, G. and B. Freedman, B., 2001. Potential for carbon sequestration in Canadian forests and agroecosystems. Mitigation and Adaptation Strategies for Global Change, 6:1-23.

Tuhkanen, S., A. Tehtila, A. and I. Savolainen, 1999. The role of $\mathrm{CH}_{4}$ and $\mathrm{N}_{2} \mathrm{O}$ emissions reductions in the cost-effective control of the greenhouse gas emissions from Finland. Mitigation and Adaptation Strategies for Global Change, 4:91-111.

\section{ACKNOWLEDGEMENTS}

Funding for this study was provided by the BIOCAP Foundation and Social Sciences and Humanities Research Council of Canada. 
Annex 1: Greenhouse gas emissions from the Canada economy

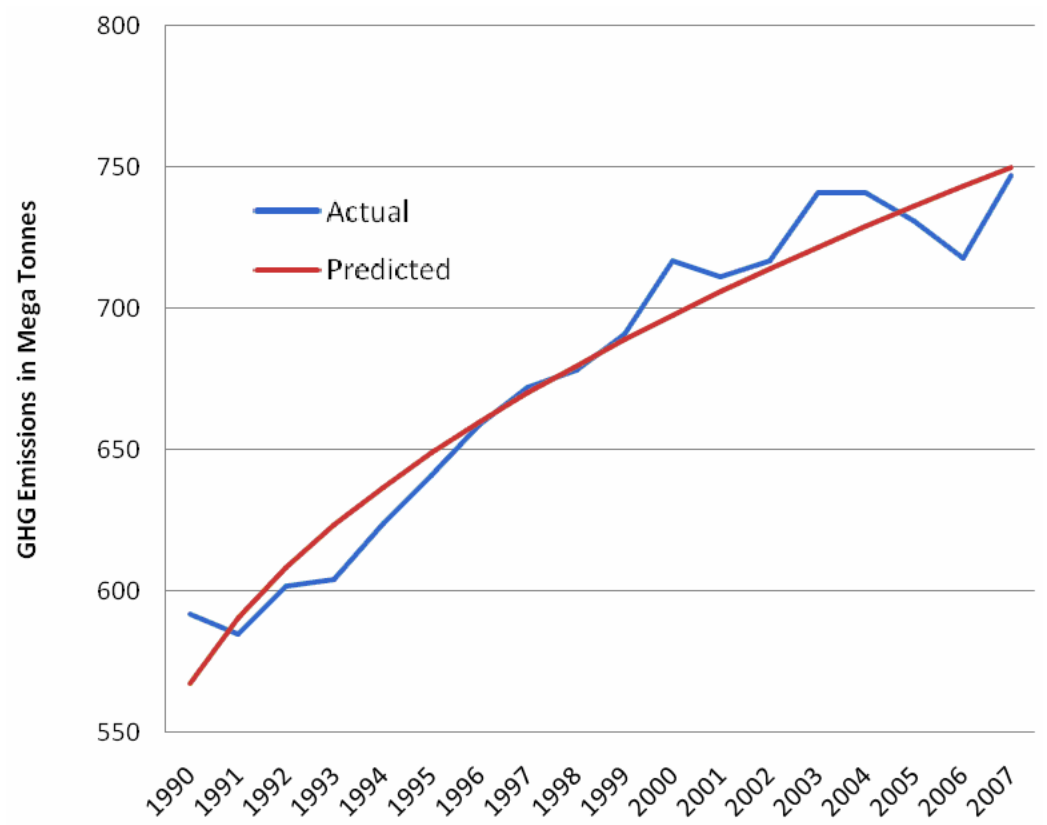

A trend equation was estiamted using a square-root transformation applied to the 19902007 data restutled in the following equation:

$$
\mathrm{GHG}_{\mathrm{t}}=510.94+56.29\left(\mathrm{TIME}_{\mathrm{t}}\right)^{0.5}
$$

$$
\mathrm{R}^{2}\left(\text { Adj- } \mathrm{R}^{2}\right)=0.946(0.942) \quad \mathrm{S}_{\mathrm{e}}=13.46 \quad \mathrm{~F}=278.48 \quad \mathrm{n}=18
$$

Where, GHG =Actual greenhosue emissions from the Canadian economy in mega tonnes (Mt);

TIME $=$ Trend variable starting from $1990=1, \ldots, 2007=18$.

Both the coefficients were significantly diifferent from zero at $1 \%$.

The above equation was used to predict 2020 GHG emissions from the Canadian economy, and were estimated at $824 \mathrm{Mt}$.

Given that 2005 level of emissions were $731 \mathrm{Mt}$, a 17\% reduction comittment by Government of Canada would translate into 2020 emissions being $607 \mathrm{Mt}$. This would result in a reduction target of $217 \mathrm{Mt}$, or $29 \%$ of the $2005 \mathrm{GHG}$ emisions level. 
Annex 2: Accounting structure used in the GHGEM

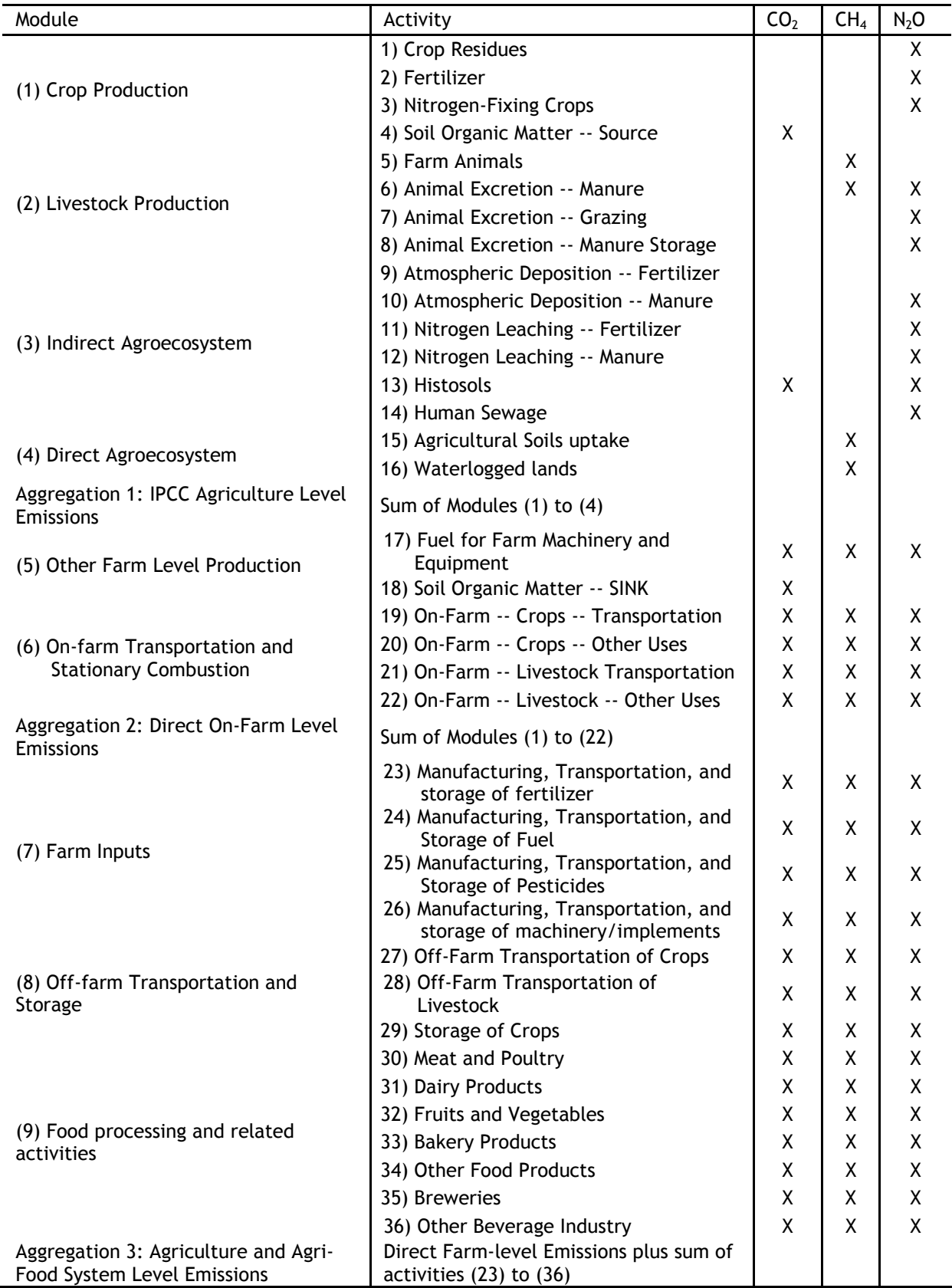

Source: Sobool and Kulshreshtha (2005). 